\title{
Commentary
}

\section{Can Ebola virus become endemic in the human population?}

\author{
Gary Wong ${ }^{1,2,3}$, George F. Gao ${ }^{3,4,5}$, Xiangguo Qiu ${ }^{1,2 \bowtie}$ \\ ${ }^{1}$ Special Pathogens Program, National Microbiology Laboratory, Public Health Agency of Canada, Winnipeg, MB, Canada \\ 2 Department of Medical Microbiology, University of Manitoba, Winnipeg, MB, Canada \\ ${ }^{3}$ CAS Key Laboratory of Pathogenic Microbiology and Immunology, Institute of Microbiology, Chinese Academy of Sciences, \\ Beijing 100101, China \\ ${ }^{4}$ National Institute for Viral Disease Control and Prevention, Chinese Center for Disease Control and Prevention, \\ Beijing 100052, China \\ ${ }^{5}$ Office of Director-General, Chinese Center for Disease Control and Prevention, Beijing 102206, China \\ $\bowtie$ Correspondence: xiangguo.qiu@phac-aspc.gc.ca (X. Qiu)
}

The 2014-15 Ebola virus (EBOV) outbreak, originally reported during March 2014 in the Western African nation of Guinea, has shown itself to be resistant to traditional containment methods, with over 28,000 infections and 11,000 deaths over 18 months. Recently, news that a Scottish nurse had relapsed to EBOV disease with neurological symptoms at 10 months after recovery have astonished experts. The prolonged nature of the outbreak has led to questions whether EBOV can become endemic in the human population, an undesirable outcome due to the large amount of resources required to keep this virus under control. In this commentary, we discuss aspects EBOV disease with those caused by pathogens considered endemic in humans, as well as factors which may contribute to sustained EBOV transmission in humans.

Ebola virus (EBOV), of the genus Ebolavirus and family Filoviridae, was historically regarded as a re-emerging pathogen, in which natural infections of humans are sporadic and unpredictable, often with several years passing by before the emergence of a new case. EBOV infection is associated with high case fatality rates (CFR) in humans (up to $90 \%$ ), but past disease outbreaks due to EBOV lasted only several months on average, and fatal cases numbered at most in the hundreds (CDC.gov, 2014). As such, EBOV was considered a minor public health threat in Africa at the time. Perceptions of this virus changed when the largest documented EBOV outbreak, first reported during March 2014, ran rampant through the Western African nations of Guinea, Sierra Leone and Liberia, causing over 28,000 infections and 11,000 deaths over the past 18 months (WHO.int, 2015a).

Continued efforts by the local and international communities are having an observable effect in mostly confining
EBOV transmission within the countries mentioned above, and the numbers of new weekly cases have been declining from a peak of over 700 in mid-September 2014 (WHO.int, 2015a). Since April 5th, 2015, the numbers of new cases reported weekly have fluctuated between 9 and 35 , and this number has been less than 10 since July 26th, 2015 (Fig. 1). However, getting to zero cases overall has proven to be a challenge and of the three most heavily affected countries, only Liberia has been declared EBOV-free, on September 3rd, 2015 (WHO.int, 2015b). During this prolonged outbreak, some experts have questioned whether EBOV can become endemic within a human population (WHO Ebola Response Team, 2014) (NPR.org, 2014), a situation characterized by low levels of sustained virus transmission between humans, and the potential for a new outbreak to occur if this transmission is not successfully halted.

Can EBOV become endemic in the human population? If we contemplate other pathogens that are considered endemic within humans, such as Hepatitis B virus (HBV), Varicella Zoster virus (VZV) and human immunodeficiency virus (HIV), patients exposed to these viruses very rarely display major, specific symptoms early in the course of infection. In many cases the patients themselves do not know that they have been infected, and thus unknowingly transmit the virus to other susceptible hosts. In contrast, EBOV infection is typified by general, flu-like symptoms that rapidly progresses to severe hemorrhagic fever and multiple-organ failure within between 7-14 days, accompanied by very visible signs of disease such as rash (Feldmann et al., 2013). Patients are not known to be contagious during the incubation period (WHO.int, 2014), and the virus is primarily transmitted during advanced and terminal EBOV disease (Dowell et al., 1999). While asymptomatic infections with EBOV in humans have been documented on 


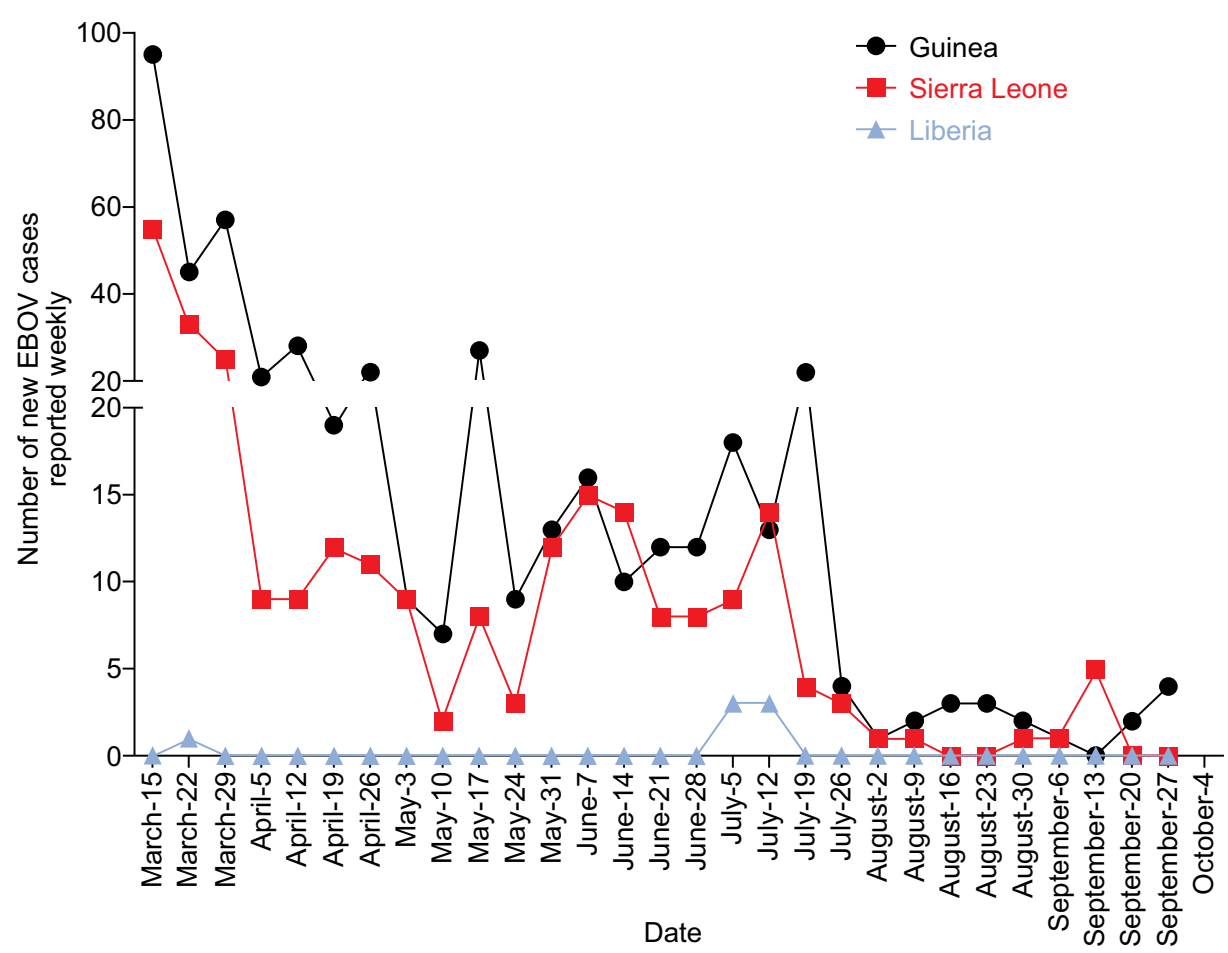

Figure 1. Numbers of new EBOV infections per week in Guinea, Sierra Leone and Liberia. Numbers are reported by the World Health Organization, and the dates are from March 15th to September 27th, 2015.

previous occasions (Baxter, 2000) (Becquart et al., 2010), there is no evidence thus far that asymptomatic humans can shed live virus. These factors prevent "silent" EBOV spread within an unsuspecting population.

On the other hand, live virus has been found in the semen of convalescent survivors at least 3 months after infection (Rowe et al., 1999) (Rodriguez et al., 1999). A Liberian female, who likely contracted EBOV after unprotected sex with a man that had recently recovered from infection (CDC.gov, 2015), showed that some EBOV survivors may still be contagious after recovery from the disease. During the 2014-15 outbreak, live EBOV has also been isolated from the ocular fluids of a physician who had survived infection, 9 weeks after the clearance of viremia (Varkey et al., 2015). The relapse of a Scottish nurse that had survived EBOV infection 10 months previously (Promedmail. org, 2015) suggests that supplementary diagnostics tests, in addition to viremia quantification by reverse transcriptionquantitative polymerase chain reaction (RT-qPCR), may be needed to confirm the elimination of EBOV in convalescent survivors. Heightened awareness regarding the possibility of recovering survivors harbouring live EBOV is necessary, but due to the lower amounts of virus present within convalescent patients compared to those with advanced EBOV disease, it is unlikely that survivors play a major role with regards to EBOV propagation in humans.

From an evolutionary standpoint, EBOV does not have a significantly higher mutation rate $\left(1.23 \times 10^{-3}\right.$ substitutions per site per year (Tong et al., 2015)) compared to other RNA viruses (Jenkins et al., 2002), and to date there are only five known member species of Ebolavirus. Published studies have also shown that EBOV is not significantly evolving, despite undergoing extensive passaging in humans during the 2014-15 outbreaks (Hoenen et al., 2015) (Tong et al., 2015). Therefore, the evidence at hand does not support the virus becoming endemic amongst the human population, and current response measures, which have steadily lowered the number of new weekly infections over time, should be sufficient in eventually ending the prolonged EBOV outbreak in Western Africa. However, the existence of possible "super-spreaders" of disease (Wong et al., 2015), and the relapse of Scottish nurse to EBOV disease is a reminder that close surveillance for any potential reoccurrence of EBOV disease in the human population is needed.

\section{FOOTNOTES}

This work was supported by the Public Health Agency of Canada (PHAC) and funded by a Canadian Safety and Security Program (CSSP) grant to X.Q. G.W. is the recipient of a Banting Postdoctoral Fellowship from the Canadian Institutes of Health Research (CIHR), and a President's International Fellowship Initiative from the Chinese Academy of Sciences (CAS). The authors declare no competing interests. Gary Wong, George F. Gao and Xiangguo Qiu declare that they have no conflict of interest. This article does not contain any 
studies with human or animal subjects performed by any of the authors.

\section{OPEN ACCESS}

This article is distributed under the terms of the Creative Commons Attribution 4.0 International License (http://creativecommons.org/ licenses/by/4.0/), which permits unrestricted use, distribution, and reproduction in any medium, provided you give appropriate credit to the original author(s) and the source, provide a link to the Creative Commons license, and indicate if changes were made.

\section{REFERENCES}

Baxter AG (2000) Symptomless infection with Ebola virus. Lancet 355:2178-2179

Becquart P, Wauquier N, Mahlakoiv T, Nkoghe D, Padilla C, Souris M, Ollomo B, Gonzalez JP, De Lamballerie X, Kazanji M et al (2010) High prevalence of both humoral and cellular immunity to Zaire ebolavirus among rural populations in Gabon. PLoS One 5: e9126

CDC.gov (2014) Outbreaks chronology: Ebola virus disease. http:// www.cdc.gov/vhf/ebola/outbreaks/history/chronology.html

CDC.gov (2015) Possible sexual transmission of Ebola virus-liberia. http://www.cdc.gov/mmwr/preview/mmwrhtml/mm64e0501a1.htm? s_cid=mm64e0501a1_x

Dowell SF, Mukunu R, Ksiazek TG, Khan AS, Rollin PE, Peters CJ (1999) Transmission of Ebola hemorrhagic fever: a study of risk factors in family members, Kikwit, Democratic Republic of the Congo, 1995. Commission de Lutte contre les Epidemies a Kikwit. J Infect Dis 179(Suppl 1):S87-S91

Feldmann H, Sanchez A, Geisbert TW (2013) Filoviridae: Marburg and Ebola viruses. Lippincott Williams and Wilkins, Philadelphia

Hoenen T, Safronetz D, Groseth A, Wollenberg KR, Koita OA, Diarra B, Fall IS, Haidara FC, Diallo F, Sanogo M et al (2015) Mutation rate and genotype variation of Ebola virus from Mali case sequences. Science 348:117-119

Jenkins GM, Rambaut A, Pybus OG, Holmes EC (2002) Rates of molecular evolution in RNA viruses: a quantitative phylogenetic analysis. J Mol Evol 54:156-165
NPR.org (2014) Endless Ebola epidemic? That's the 'risk we face now,' CDC says. http://www.npr.org/blogs/goatsandsoda/2014/ 12/15/370446566/endless-ebola-endemic-thats-the-risk-we-facenow-cdc-says

Promedmail.org (2015) Ebola update (116): WHO, Scottish nurse relapse, suspected, research, funding. http://www.promedmail. org/direct.php?id=3708317

Rodriguez LL, De Roo A, Guimard Y, Trappier SG, Sanchez A, Bressler D, Williams AJ, Rowe AK, Bertolli J, Khan AS et al (1999) Persistence and genetic stability of Ebola virus during the outbreak in Kikwit, Democratic Republic of the Congo, 1995. J Infect Dis 179(Suppl 1):S170-S176

Rowe AK, Bertolli J, Khan AS, Mukunu R, Muyembe-Tamfum JJ, Bressler D, Williams AJ, Peters CJ, Rodriguez L, Feldmann $\mathrm{H}$ et al (1999) Clinical, virologic, and immunologic follow-up of convalescent Ebola hemorrhagic fever patients and their household contacts, Kikwit, Democratic Republic of the Congo. Commission de Lutte contre les Epidemies a Kikwit. J Infect Dis 179(Suppl 1):S28-S35

Tong YG, Shi WF, Liu D, Qian J, Liang L, Bo XC, Liu J, Ren HG, Fan $\mathrm{H}$, Ni M et al (2015) Genetic diversity and evolutionary dynamics of Ebola virus in Sierra Leone. Nature 524:93-96

Varkey JB, Shantha JG, Crozier I, Kraft CS, Lyon GM, Mehta AK, Kumar G, Smith JR, Kainulainen MH, Whitmer S et al (2015) Persistence of Ebola virus in ocular fluid during convalescence. N Engl J Med 372:2423-2427

WHO Ebola Response Team (2014) Ebola virus disease in West Africa-the first 9 months of the epidemic and forward projections. N Engl J Med 371:1481-1495

WHO.int (2014) WHO-frequently asked questions on Ebola virus disease. http://www.who.int/csr/disease/ebola/faq-ebola/en/

WHO.int (2015a) Ebola situation report-13 May 2015. http://apps. who.int/ebola/en/current-situation/ebola-situation-report-13-may2015

WHO.int (2015b) Ebola transmission in Liberia over. Nation enters 90-day intensive surveillance period. http://www.who.int/mediacentre/ news/statements/2015/ebola-transmission-over-liberia/en/

Wong G, Liu W, Liu Y, Zhou B, Bi Y, Gao GF (2015) MERS, SARS, and Ebola: the role of super-spreaders in infectious disease. Cell Host Microbe 18:398-401 